\title{
La respuesta de la política fiscal a la actividad económica en los países desarrollados
}

\author{
JUAN A. CERÓN \\ Departamento de Economía de la Empresa. UNIVERSIDAD CARLOS III DE MADRID, \\ ESPAÑA. E-mail: jceron@emp.uc3m.es
}

\begin{abstract}
RESUMEN
Este trabajo examina cómo ha respondido la política fiscal discrecional a las oscilaciones económicas en un conjunto de países de la OCDE a lo largo de las últimas cuatro décadas. En línea con la reciente literatura, utilizamos el Saldo Estructural Primario como indicador para caracterizar la actividad fiscal de los Gobiernos. Los resultados muestran el escaso uso de la política fiscal en coyunturas de expansión o recesión así como un marcado activismo en situaciones de estabilidad económica. Se analizan las razones para este comportamiento escasamente convencional, se incide en el distinto comportamiento de impuestos y gastos, se valora la importancia que tiene la posición fiscal de partida y se examina el grado de acomodo de la política monetaria.
\end{abstract}

Palabras clave: Política Fiscal, estabilización económica, ciclos, globalización.

\section{Fiscal Policy Reaction to Economic Activity in Developed Countries}

\begin{abstract}
This paper studies how discretional fiscal policy has reacted to economic fluctuations in a group of OCDE countries during the last four decades. Following the recent literature, we use the cyclically adjusted primary balance as a tool to identify government fiscal activity. The results suggest a limited use of fiscal policy in expansion or recession circumstances just as a marked activity in economic stability situations. The reasons behind this performance barely conventional will be examined; we analyze the different responses of taxes and expenditures, pay attention to the importance of fiscal policy at the beginning and evaluate the monetary policy accommodation.
\end{abstract}

Keywords: Fiscal Policy, Output Stability, Cycles, Globalization.

Clasificación JEL: E62, E65

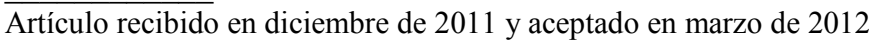

Artículo disponible en versión electrónica en la página www.revista-eea.net, ref. ə-30114 


\section{INTRODUCCIÓN}

La historia del desempeño de la política fiscal muestra una evolución cuanto menos llamativa. Durante las décadas inmediatamente posteriores a la Segunda Guerra Mundial fue considerada, tanto en los ámbitos académicos como en los políticos, como la principal y en ocasiones única herramienta estabilizadora de política económica. A partir de la década de los setenta y como consecuencia de su incapacidad para dar respuesta a la existencia simultanea de paro e inflación, fue sustituida progresivamente por la política monetaria en el papel central de amortiguar las oscilaciones del ciclo. La denominada economía neoclásica proporcionó el correspondiente sustento teórico.

La posición contraria al uso de la política fiscal para la gestión de la demanda agregada presenta distintas vertientes. En primer lugar están quienes no son partidarios de que los Gobiernos influyan en los ciclos económicos, bajo el razonamiento de que si las perturbaciones que determinan la evolución de la economía son exógenas, cualquier intervención de la política económica -monetaria o fiscal- incidirá negativamente en el funcionamiento de los mercados (Dagum, 2010, p. 581). La limitación de la amplitud de los ciclos reducirá la riqueza a largo plazo al menoscabar el crecimiento económico, de manera que las ganancias acumuladas de bienestar derivadas de un mayor crecimiento tendencial serían sustancialmente superiores a las derivadas de una suavización del ciclo (Sutherland et al., 2010, p. 49). El mejor exponente teórico de este planteamiento es la denominada "Teoría del ciclo real". Un segundo grupo de razones tiene que ver con quienes asumen la bondad de la estabilización económica pero confían este objetivo a la política monetaria, quedando relegado el papel de la política fiscal al que puedan desempeñar los estabilizadores automáticos. Un tercer grupo defiende la existencia de multiplicadores fiscales negativos. Desde la aparición del trabajo de Giavazzi y Pagano (1990), ha ido ganando crédito la idea de que, bajo determinadas circunstancias, una política fiscal de ajuste puede generar efectos expansivos a corto plazo. Es lo que se conoce como "Contracción fiscal expansiva": si el anuncio de una disminución futura del déficit público es creíble para los agentes económicos, se reducirán los tipos de interés a largo plazo, lo que incidirá a corto plazo sobre la demanda agregada de manera positiva.

Uno de los argumentos que lleva a muchos economistas a defender la conveniencia de suavizar los ciclos económicos son las consecuencias en términos de desempleo que se producen en las fases recesivas de las economías. De ahí que James Tobin indicara que los costes sociales del desempleo son mayores que cualquier otro tipo de pérdida de eficiencia derivada de la intervención pública 
en la economía (Tobin, 1977, p. 461) ${ }^{1}$, por lo que reducir la variabilidad de los ciclos será beneficioso para la sociedad en su conjunto. Además, la suavización de las oscilaciones reduce la incertidumbre económica a la que se enfrentan los agentes privados y el Gobierno, permitiéndoles planificar mejor el futuro.

En el seno de quienes respaldan el papel estabilizador de la política económica y dentro de ella las bondades la política fiscal, el conocimiento comúnmente aceptado sobre este particular es que la política fiscal debería comportarse de manera anticíclica, aunque su impacto estabilizador es débil y tardío, especialmente comparado con la política monetaria; no es simétrica, más activa en recesiones y más acomodaticia en expansiones, mientras que tanto la política monetaria como los estabilizadores automáticos actúan con una mayor simetría. En condiciones macroeconómicas no extremas, el verdadero papel anticíclico en la esfera fiscal deben desempeñarlo los estabilizadores automáticos. Por último, se piensa que se recurre con mayor frecuencia al uso de los gastos que al de los ingresos, especialmente en momentos recesivos.

En el campo empírico abundan las contribuciones dedicadas al estudio del impacto a corto plazo de la política fiscal sobre la actividad económica, es decir, de los multiplicadores fiscales ${ }^{2}$. Sin embargo, es menor el número de los que se centran en la respuesta de la actividad fiscal a las oscilaciones de la economía. $\mathrm{Y}$ es importante el análisis de la función de reacción de la política fiscal porque de las características que presente, del cómo y en qué condiciones se materialice, va a depender en gran medida su éxito; además, su seguimiento ayuda a establecer la trazabilidad de las magnitudes fiscales de un país.

Los resultados de las investigaciones son diversos. Fatás y Myhov (2009) encuentran que la política fiscal se ha comportado de forma ligeramente procíclica en la zona euro y apenas ha cambiado desde la introducción de la moneda única, y sitúan a los criterios impuestos por el Tratado de Maastricht primero y el Pacto de Estabilidad y Crecimiento después en el origen de este comportamiento; por el contrario, en EE.UU. la respuesta durante los últimos diez años ha sido anticíclica, debido a las reducciones de impuestos en momentos de recesión. También Galí y Perotti (2003) analizan la respuesta de la política fiscal en los países de la zona euro y encuentran que el Tratado de Maastricht no induce un perfil más procíclico de la misma. Égert (2010) conclu-

\footnotetext{
${ }^{1}$ Se refería en concreto Tobin a las pérdidas de bienestar ocasionadas por la intervención pública en los mercados, que tienen su expresión más conocida en el denominado "Triángulo de Harberger".

${ }^{2}$ El trabajo de Spilimbergo et al. (2009) contiene, en su Apéndice II, una presentación de las cuestiones metodológicas que afectan a la medición del impacto de las actuaciones fiscales así como abundantes referencias a los cálculos realizados en un número considerable de estudios. Por su parte, Hemming et al. (2002, Sección III) realiza una revisión de la literatura empírica y una presentación de las estimaciones, discriminando en función de la técnica utilizada.
} 
ye que la política fiscal discrecional en los países de la OCDE no tiene un perfil nítido respecto al ciclo económico y, en cualquier caso, la respuesta está lejos de ser lineal, dependiendo especialmente de las condiciones de partida de las magnitudes fiscales. Leigh y Stehn encuentran un comportamiento contracíclico en los países anglosajones del G-7 (Canadá, Reino Unido y EE.UU.), y procíclico en el resto de ese grupo, con una ligera tendencia para todos hacia un comportamiento más contracíclico (o menos procíclico) $(2009$, p. 5). Otro grupo de trabajos aborda el perfil cíclico no sólo del saldo fiscal sino asimismo de sus distintos componentes, dado que la respuesta respecto del ciclo pudiera compensarse entre ellos, proporcionando una visión distorsionada. Así, Lane (2003, p. 2668) señala que hay un alto grado de heterogeneidad en el comportamiento cíclico de los distintos capítulos del gasto público. Alesina y Perotti (1995, p. 30), observan que las expansiones fiscales descansan básicamente en el gasto mientras que los grandes ajustes suelen sustentarse en incrementos de impuestos y que la composición de las actuaciones fiscales es determinante para su éxito, especialmente en el caso de los ajustes. El FMI (2008, p. 167) para la OCDE y Leigh y Stehn (2009) para el G-7 encuentran, en fin, asimetría en la respuesta fiscal, más proclive a tener presencia en recesiones que en expansiones.

El objetivo de este trabajo consiste en analizar los patrones de comportamiento de la política fiscal en los países desarrollados durante las últimas décadas y contrastar esta caracterización con la visión convencional. Para ello, se ha realizado un análisis de eventos sobre una base de datos con información macroeconómica y fiscal de 24 países de la OCDE (de los que 11 pertenecen a la Unión Económica y Monetaria) que abarca el periodo 1970-2008, y que gira alrededor de dos conceptos clave: la posición de la economía en el ciclo económico y la actividad fiscal discrecional. Este análisis de eventos nos ha permitido abordar las siguientes tareas: i) En primer lugar, establecer las características de la respuesta de la política fiscal a las fluctuaciones en el ciclo económico, no solo en épocas de crisis o de expansión sino también de atonía; ii) A continuación, estudiar el marco monetario y de finanzas públicas en el que se produce la actuación fiscal; iii) Finalmente, contrastar nuestros resultados con los obtenidos en la literatura académica y elaborar conclusiones de política económica.

Nuestra investigación contribuye a la literatura existente en varias direcciones. En primer lugar, presenta una amplia cobertura de la actividad fiscal, incluyendo la que se produce en situaciones planas de la economía. En segundo lugar, la caracterización de la respuesta se hace desde una visión integradora, para lo cual utilizamos distintas perspectivas de análisis. Por último, incorporamos un análisis del comportamiento cíclicamente contradictorio de ingresos y gastos.

Las principales cuestiones a las que intentaremos dar respuesta son las siguientes: 
- ¿Ha respondido siempre la política fiscal discrecional a las oscilaciones de la economía o lo ha hecho sólo ocasionalmente?

- Por el contrario, ¿ha actuado también de manera proactiva en escenarios de reducida brecha productiva, sin recesión ni expansión? Dicho de otra forma: ¿responde la política fiscal discrecional a criterios distintos de la estabilización económica?

- ¿Se confirma la asimetría de la política fiscal, más proclive a actuar en recesiones que en expansiones?

- ¿Podemos corroborar la mayor frecuencia de uso discrecional de los gastos que de los ingresos? Y si es así, ¿en qué fases del ciclo? Por último, ¿actúan en la misma dirección respecto del ciclo gastos e impuestos cuando son utilizados simultáneamente?

- ¿Hasta qué punto es importante el marco fiscal previo? Es decir, ¿cómo influye en la respuesta fiscal la posición de inicio de variables como la deuda pública, el déficit fiscal o el tamaño del sector público?

- ¿Presenta la política fiscal un perfil particular en los países pertenecientes a la UEM?

- Respecto al policy-mix, nos preguntamos si ha existido concordancia en el comportamiento cíclico entre la política fiscal y la monetaria, esto es, si la política monetaria se ha acomodado a la política fiscal.

Nuestros resultados confirman la escasa utilización de la política fiscal para estabilizar las economías de los países desarrollados a lo largo de las últimas cuatro décadas. Además, esta actividad ha tenido un carácter asimétrico, más tendente a aparecer en recesiones que en expansiones, lo que nos lleva a concluir que en expansiones, la estabilización económica ha recaído de manera casi exclusiva en la política monetaria y en los estabilizadores automáticos, mientras que en las recesiones también ha sido protagonista la política fiscal. En contraposición, hemos constatado que existe significativa actividad fiscal al margen de las oscilaciones de la economía lo que, además de convertirse en ocasiones en una fuente de volatilidad del ciclo, nos sugiere la reflexión de que la política fiscal, antes que a la reducción de la amplitud de los ciclos, atiende más a otras metas como la consolidación de las cuentas públicas o el crecimiento a largo plazo.

En cuanto a las variables de entorno, la respuesta fiscal no se produce de manera lineal sino que está condicionada por la situación previa de las finanzas públicas. Los niveles de deuda y de déficit son elementos determinantes para explicar el tono cíclico de la política fiscal, de manera que en no pocas ocasiones prevalece el objetivo de la consolidación de las cuentas públicas frente a los de impulsar la economía o la creación de empleo. En cuanto a la política mone- 
taria, catalizador importante para el éxito de las políticas fiscales, confirmamos que no ha existido acomodo a la política fiscal.

\section{METODOLOGÍA}

Existen básicamente dos maneras de aproximarse a la respuesta de la actividad fiscal ante los cambios en la actividad económica. De un lado, la realización de una regresión lineal en la que la variable dependiente es alguna magnitud fiscal (como el Saldo Primario o el Saldo Primario Ajustado de Ciclo) y donde los regresores suelen ser variables como la situación cíclica de la economía, retardos de la propia variable dependiente y de otras magnitudes fiscales, asimismo contemporáneas o retardadas. Los trabajos de Fatás y Myhov (2009), Galí y Perotti (2003), Lane (2003) y Égert (2010) entrarían en este grupo. Otras investigaciones prefieren centrarse en estudiar únicamente los cambios de una cierta envergadura, tanto en la situación económica como en las variables fiscales, para evitar así la contaminación de efectos cíclicos o de otro tipo, y considerando que una variación importante en las magnitudes fiscales será el resultado de decisiones adoptadas por el Gobierno. En las investigaciones de Alesina y Perotti (1995 y 1997), FMI (2008) y Leigh y Stehn (2009) se sigue este enfoque. Nuestro trabajo va en esta segunda línea ${ }^{3}$. Este planteamiento requiere la definición previa de qué se entiende por un cambio relevante en la posición cíclica de la economía o en la posición fiscal, cuestión que abordamos a continuación.

\subsection{Definición y medida de recesión y expansión económica}

Delimitar qué es una recesión o una expansión económica es algo inevitablemente subjetivo. Asumimos, con la literatura reciente (Alesina y Perotti, 1995, FMI, 2008, Leigh y Steh, 2009), la conveniencia de considerar no sólo la tasa de variación del PIB sino también la posición en el ciclo económico. La propia Unión Europea, en el pilar correctivo del Pacto de Estabilidad y Crecimiento y tras su modificación en 2005, define -ciertamente de una forma un tanto ambigua- una "recesión económica severa" como aquella en la que se produce una tasa de crecimiento negativa o un crecimiento continuada y significativamente por debajo del crecimiento potencial ${ }^{4}$. Por su parte, la OCDE establece los conceptos de recesión y expansión económica a partir de la posición cíclica de la economía, medida por el ouput-gap o brecha de producción, y definida ésta

\footnotetext{
3 Tanto las contribuciones referenciadas como la nuestra propia trabajan con datos macroeconómicos y fiscales "definitivos", pero las decisiones fiscales se adoptaron en su momento con los datos disponibles entonces, en gran medida revisados posteriormente. Esto confiere un sesgo a estos estudios. Una revisión de la reciente literatura sobre este particular se encuentra en Cimadomo (2011).

${ }^{4}$ Consejo de la Unión Europea del 20 de marzo de 2005.
} 
como la diferencia entre el nivel de la actividad real de la economía y el nivel que podría alcanzar potencialmente sin acelerar la tasa de inflación, como proporción de la producción potencial (OCDE, $2008 \mathrm{~b}$, Box.1) $)^{5}$. Cuando el output-gap es positivo significa que la producción real excede la potencial, esto es, hay un exceso de demanda, lo cual tiende a presionar los precios al alza. Cuando el output-gap es negativo, significa que la demanda nacional es inferior a la oferta ${ }^{6}$.

¿Cuándo consideramos una brecha de producción negativa suficientemente amplia como para calificarla como "recesión"?. En este punto, seguimos la definición aportada por Leigh y Stehn $(2009$, p. 3) y por el Fondo Monetario Internacional (2008, p. 187), según la cual una recesión es un periodo en el que el crecimiento es negativo o el output-gap (con datos centrados) sea negativo y se sitúe por debajo de una vez su desviación típica.

Recesión $\left\{\begin{array}{l}\text { PIB negativo } \\ o \\ \text { Output-gap }<-1 \text { desviación típica del output-gap }\end{array}\right.$

Con esta definición:

- Output-gaps negativos pero que sean usuales en un país no serán considerados como "recesión"; sólo aquellos que se salgan de lo normal para cada país.

- Habrá situaciones en las que el crecimiento del PIB pueda ser positivo y sin embargo ser consideradas recesivas, si dicho crecimiento se encuentra suficientemente alejado del crecimiento potencial.

Análogamente, consideramos expansión económica aquella situación con PIB positivo y output-gap positivo y mayor que una desviación típica.

Expansión $\left\{\begin{array}{l}\text { PIB positivo } \\ \mathrm{y} \\ \text { Output-gap }>+1 \text { desviación típica del output-gap }\end{array}\right.$

Todas las demás situaciones tendrán la consideración de situación económica plana.

\footnotetext{
${ }^{5}$ Para la metodología de cálculo del PIB potencial, ver OCDE Economic Outlook: Sources and Methods. URL permanente:

http://www.oecd.org/document/14/0,3343,en_2649_34573_1847822_1_1_1_1,00.html

${ }^{6}$ Una dificultad intrínseca alrededor del concepto de PIB potencial es que la actividad potencial es, por definición, inobservable, de manera que las decisiones de política macroeconómica que se basen en estimaciones de esta variable o de otras que a su vez se calculen a partir de la misma (como el output-gap), están sujetas a un grado importante de incertidumbre.
} 
Economía Plana $\left\{\begin{array}{l}\text { PIB positivo } \\ \text { y } \\ \text { Output-gap } \leq \mid 1 \text { desviación típica del output-gap | }\end{array}\right.$

\subsection{Definición y medida da la actividad fiscal discrecional}

Los saldos fiscales (déficits o superávits) pueden modificarse entre dos momentos del tiempo por dos motivos: porque algunos ingresos o gastos varíen (de manera pasiva) con la evolución de la economía (así, si la economía crece, también lo harán lógicamente los ingresos impositivos) o porque el Gobierno tome decisiones de política económica que influyan (de manera activa) sobre las cuentas públicas.

La magnitud fiscal que mejor refleja la actuación del Gobierno es el cambio en el denominado Saldo Estructural Primario (o Saldo Primario Ajustado de Ciclo), que es el saldo residual tras eliminar los gastos financieros netos así como el componente cíclico, aquel que depende de la coyuntura económica ${ }^{7}$. Las variaciones en el Saldo Estructural Primario (SEP) entre dos periodos serán la consecuencia, por tanto, de las decisiones fiscales de los Gobiernos ${ }^{8}$. El siguiente paso es determinar cuándo una variación en el SEP es suficientemente amplia como para considerar que es el resultado de una actuación fiscal discrecional.

Definiremos la política fiscal discrecional según el siguiente criterio:

- Estímulo fiscal: Variación anual del SEP $<-0,5$ desviación típica

- Ajuste fiscal: Variación anual del SEP $>+0,5$ desviación típica

- Neutral: $-0,5$ desviación típica $\leq$ Variación anual del SEP $\leq+0,5$ desviación típica

La razón por la que tenemos en cuenta la dispersión propia de los datos de cada país es porque un incremento de, digamos, un 1\% en el SEP no significa lo mismo para Alemania u Holanda que para Grecia o Italia. Hay que decir que, a efectos prácticos, 0,5 desviaciones típicas representan, en promedio para los países cubiertos, algo más de un punto porcentual de PIB, siendo los casos extremos Italia e Irlanda por arriba (1,9 puntos porcentuales de PIB) y Francia por abajo ( 0,5 puntos); quiere decirse que para Italia o Irlanda, se considerará que existe impulso fiscal cuando la variación anual de su SEP sea superior a 1,9 puntos porcentuales de PIB, mientras que para Francia asumiremos que existe

\footnotetext{
${ }^{7}$ Para la metodología de cálculo del SEP ver Girouard y André (2005).

${ }^{8}$ En realidad, las variaciones en el SEP no son exclusivamente el reflejo de las decisiones de política fiscal de los Gobiernos. Es decir, una vez depurado el saldo primario de los efectos cíclicos, aun quedan otros elementos explicativos de las variaciones en el saldo estructural primario que no son el resultado de las políticas fiscales; por ejemplo, las oscilaciones en el precio de los activos, cambios en la composición de la demanda agregada o acontecimientos de carácter extraordinario.
} 
estímulo fiscal cuando la variación anual de su SEP sea superior a 0,5 puntos porcentuales de su PIB.

¿Cómo abordan este punto otros estudios? Alesina y Perotti (1995, p. 8 y 1997, p. 220), siguiendo a Blanchard (1990), consideran el Saldo Primario (que es el saldo fiscal una vez eliminados los gastos e ingresos financieros) como la mejor variable para representar la política fiscal discrecional, bajo la restricción de que la tasa de desempleo no se hubiera modificado respecto del año anterior, para purgar así los datos del componente coyuntural. Este indicador tiene la ventaja de que no necesita estimar la producción potencial y por tanto el outputgap. A partir de esta variable, consideran un impulso fiscal si la variación frente al año precedente es mayor de 0,5 puntos porcentuales de PIB. Distingue entre pequeños y grandes estímulos; estos últimos se alcanzarían si la variación es superior a 1,5 puntos porcentuales. Estos autores prueban asimismo a estimar el impulso fiscal teniendo en cuenta la variabilidad propia de los datos para cada país -como hacemos nosotros-, con el resultado de que los valores finales prácticamente no varían. Giavazzi et al. (2005, p. 199), utilizando como variable de referencia el déficit de pleno empleo consideran "grandes y persistentes impulsos fiscales" cuando su valor es superior a 1,5 puntos del PIB potencial. Más recientemente, Leigh y Stehn $(2009$, p. 4), establecen como límite una variación del SEP de 0,25 puntos porcentuales de PIB durante un trimestre. Y el FMI utiliza también una frontera de 0,25 puntos porcentuales de PIB para datos trimestrales (FMI, 2008, p. 166). Esta referencia es comparable a la nuestra, puesto que, extrapolando, supone alrededor de un punto de PIB en términos anuales, similar al promedio obtenido con nuestro criterio, con la diferencia de que nosotros tenemos en cuenta los valores propios de cada país, lo que nos permite identificar sólo aquellas oscilaciones que son inusualmente amplias.

\subsection{Otras variables}

Un cambio en el Saldo Cíclico, que es el que depende sólo de la posición cíclica de la economía, se considera significativo si es superior en valor absoluto a 0,25 desviaciones de sus datos históricos. Hemos preferido 0,25 desviaciones frente al criterio de 0,5 desviaciones adoptado para el SEP debido a que la magnitud del saldo cíclico es comparativamente bastante menor.

Como también pretendemos analizar el comportamiento por separado de ingresos y gastos de tipo discrecional en las actuaciones fiscales (esto es, los ingresos y gastos ajustados de ciclo o estructurales), definiremos un cambio significativo de los mismos como una variación anual de 0,25 veces la desviación típica de sus datos históricos. Hemos preferido 0,25 en lugar de 0,5 por la menor volatilidad de los ingresos o gastos (como proporción del PIB) cuando son considerados independientemente que cuando son evaluados de manera agregada en el saldo fiscal, debido a que en el mismo suman sus efectos. 
Por último, y a efectos de comparar la respuesta de la política fiscal con la de la política monetaria, consideramos que los tipos de interés a corto plazo representan adecuadamente el tono de la política monetaria, con una variación superior a 0,5 puntos porcentuales en los tipos nominales a tres meses como dintel para considerar un cambio suficientemente significativo. Tanto Leigh y Stehn (2009, p. 4) como el FMI (FMI, 2008, p. 187), fijan este indicador, para datos trimestrales no anualizados, en 0,25 puntos. Nosotros hemos optado por una variación superior debido a que trabajamos con datos anuales.

\subsection{Alcance temporal y fuentes de datos}

La serie comienza en 1970 y finaliza en 2008 debido a que las circunstancias macroeconómicas y fiscales posteriores a ese ejercicio son tan particulares que distorsionarían los resultados para los otros treinta y nueve años.

Todos los datos se han obtenido de la Economic Outlook Database de la OCDE, a excepción de los correspondientes a ingresos y gastos ajustados de ciclo, que se han tomado de la base de datos AMECO (Comisión Europea), y sólo para los países que pertenecen a la Unión Europea. Esta es la razón por la que el estudio y las conclusiones relativas a ingresos y gastos estructurales se refieren exclusivamente a este colectivo.

\section{RESULTADOS}

La aplicación, país a país y año a año, de los criterios expuestos en el anterior apartado para identificar crisis y expansiones económicas, por un lado, y actuaciones fiscales expansivas o contractivas por otro, nos proporciona el conjunto de los casos de estudio, cuya relación se contiene en los Anexos 1 y 2, respectivamente. El Anexo 3, por su parte, proporciona una visión de los datos agregados.

\subsection{La orientación cíclica de la respuesta fiscal}

La Tabla 1 resume el comportamiento cíclico de la política fiscal. Las reflexiones que nos merece son:

1. La escasa actividad fiscal en momentos que, según el conocimiento al uso, requerirían de su presencia; en más de dos de cada tres (69\%) situaciones con la economía en expansión, no ha existido política fiscal discrecional; esta proporción baja a una de cada dos en momentos de recesión (56\%). Por el contrario, encontramos un elevado activismo fiscal en situaciones de economía plana: el $40 \%$ de las mismas presenta actividad fiscal relevante.

2. Desde la perspectiva del ciclo económico, la política fiscal es con mayor frecuencia procíclica que anticíclica en coyunturas expansivas, mientras 
que en recesiones es ligeramente anticíclica. Obsérvese cómo sólo en uno de cada cuatro episodios de recesión la política fiscal ha sido anticíclica.

Tabla 1

Política fiscal discrecional en relación con el ciclo económico

\begin{tabular}{|c|c|c|c|c|c|c|c|c|}
\hline & \multicolumn{8}{|c|}{ Situación económica } \\
\hline & \multicolumn{3}{|c|}{ Expansión } & \multicolumn{3}{|c|}{ Recesión } & \multicolumn{2}{|c|}{ Plana } \\
\hline & $\begin{array}{l}\mathrm{N}^{0} \text { de } \\
\text { casos }\end{array}$ & $\%$ & Sentido & $\begin{array}{l}\mathrm{N}^{\circ} \mathrm{de} \\
\text { casos }\end{array}$ & $\%$ & Sentido & $\begin{array}{l}\mathrm{N}^{\circ} \mathrm{de} \\
\text { casos }\end{array}$ & $\%$ \\
\hline \multicolumn{9}{|l|}{ OCDE } \\
\hline Estímulo fiscal & 21 & $19 \%$ & Pro & 40 & $24 \%$ & Contra & 79 & $17 \%$ \\
\hline Ajuste fiscal & 14 & $13 \%$ & Contra & 33 & $20 \%$ & Pro & 109 & $23 \%$ \\
\hline Neutralidad & 77 & $69 \%$ & - & 92 & $56 \%$ & - & 275 & $60 \%$ \\
\hline \multicolumn{9}{|l|}{ UE 11} \\
\hline Estímulo fiscal & 15 & $24 \%$ & Pro & 14 & $17 \%$ & Contra & 42 & $19 \%$ \\
\hline Ajuste fiscal & 5 & $8 \%$ & Contra & 23 & $28 \%$ & Pro & 49 & $22 \%$ \\
\hline Neutralidad & 42 & $68 \%$ & - & 44 & $54 \%$ & - & 131 & $59 \%$ \\
\hline \multicolumn{9}{|l|}{ OCDE-UE11 } \\
\hline Estímulo fiscal & 6 & $12 \%$ & Pro & 26 & $31 \%$ & Contra & 37 & $16 \%$ \\
\hline Ajuste fiscal & 9 & $18 \%$ & Contra & 10 & $12 \%$ & Pro & 56 & $24 \%$ \\
\hline Neutralidad & 35 & $70 \%$ & - & 48 & $57 \%$ & - & 144 & $60 \%$ \\
\hline
\end{tabular}

(1) Pro = procíclico Contra = contracíclico

Fuente: Elaboración propia a partir de OCDE Economic Outlook Database.

En la desagregación entre los países que forman parte de la zona euro y el resto de economías de la OCDE se observan comportamientos distintos. En la primera el sesgo procíclico está muy acentuado, tanto en recesiones como en expansiones. De manera complementaria, el grupo formado por el resto de países de la OCDE tiene un desempeño anticíclico, especialmente en recesiones. Analizados en perspectiva histórica los datos de la zona euro (Anexo 2), se observa que la mayor proporción de actuaciones procíclicas ocurre antes de 1992, año en que se aprueba el Tratado de la Unión. A partir de entonces, la política fiscal en esta zona se vuelve acíclica, pero no en el sentido de que sea en ocasiones procíclica y otras anticíclica, sino de que la política fiscal relacionada con el ciclo prácticamente desaparece del escenario europeo. 


\section{2. ¿Cuál ha sido el tamaño de la respuesta fiscal?}

A primera vista, el tamaño de la respuesta fiscal discrecional ante situaciones de recesión o expansión ha sido pequeño, unas pocas décimas del PIB, y en ambos casos en el mismo sentido (expansivo), confirmando su papel escasamente anticíclico cuando la brecha de producción es negativa, y ligeramente procíclico cuando es positiva (Tabla 2, "Todos los casos"). Además, es el componente cíclico del balance fiscal (los estabilizadores automáticos), el que determina la volatilidad del balance primario, tanto en signo como en volumen ${ }^{9}$. Estos valores son similares a los obtenidos por el FMI (2008, Gráfico 5.1).

Tabla 2

Tamaño medio de la respuesta fiscal (\% del PIB)

\begin{tabular}{lccc} 
& & \multicolumn{2}{c}{ Situación económica } \\
\cline { 3 - 4 } & & Expansión & Recesión \\
\hline \multirow{3}{*}{ Todos los casos } & SP & 0,3 & $-0,9$ \\
& SEP & $-0,3$ & $-0,2$ \\
& SC & 0,5 & $-0,7$ \\
\hline \multirow{3}{*}{ Impulso fiscal } & SP & $-1,2$ & $-3,0$ \\
& SEP & $-1,7$ & $-2,3$ \\
\hline \multirow{3}{*}{ Ajuste fiscal } & SC & 0,5 & $-0,8$ \\
& SP & 2,8 & 1,6 \\
& SEP & 2,2 & 2,1 \\
\hline
\end{tabular}

$S P=$ Saldo Primario

$S E P=$ Saldo Estructural Primario

$S C=$ Saldo Cíclico

Fuente: Elaboración propia a partir de OCDE Economic Outlook Database.

Sin embargo, un análisis más profundo de los datos nos conduce a otras reflexiones. Tal y como se ha comentado anteriormente, el sentido de las reacciones del SEP no es uniforme. Durante coyunturas recesivas ha tenido a veces un perfil expansivo y a veces contractivo, y otro tanto pero en sentido contrario ha ocurrido durante los momentos de crecimiento. Merece la pena por tanto discriminar el tamaño de las variaciones de las distintas magnitudes fiscales a partir de la reacción de la política fiscal discrecional. Desde esta perspectiva, la

\footnotetext{
${ }^{9}$ En ocasiones, se considera que la función de estabilización automática no solamente procede de estos instrumentos sino también, o incluso principalmente, del gasto público considerado "acíclico", que no se ve modificado con el ciclo; por ejemplo, los gastos en enseñanza, los sueldos de los funcionarios, sanidad o pensiones, no se reducen prácticamente nunca como consecuencia de una reducción del PIB.
} 
respuesta anticíclica de esta última ha presentado un tamaño similar en valores absolutos en recesiones y expansiones, $2,3 \%$ y $2,2 \%$ del PIB respectivamente (Tabla 2). Y junto con el papel de los estabilizadores automáticos -en cualquier caso anticíclico- coloca el valor medio del Saldo Primario en -3,0\% del PIB en recesiones y $+2,8 \%$ del PIB en expansiones.

Por otro lado observamos que, en realidad, cuando hay respuesta fiscal activa -independientemente de su signo cíclico-, la volatilidad del balance primario depende, tanto en signo como en tamaño, más de las políticas discrecionales adoptadas que de la fuerza de los estabilizadores automáticos. De esta forma y en promedio, cuando la política discrecional es procíclica, el balance primario también lo es, porque el impacto de la misma es superior al de los estabilizadores. Es decir, cuando la política fiscal discrecional es relevante, es la que explica las variaciones del saldo primario, no los estabilizadores automáticos.

\section{3. ¿Qué instrumento, impuestos o gastos?}

Dado el comportamiento un tanto errático de la política fiscal, hemos analizado con más detalle la respuesta por separado de impuestos y gastos, en ambos casos tras descontar el componente coyuntural y los gastos financieros. ¿En qué medida se han utilizado los impuestos o los gastos públicos proactivamente para incidir en la coyuntura económica? ${ }^{10}$

La respuesta de los impuestos a las oscilaciones económicas ha sido predominantemente procíclica, tanto en recesiones como en expansiones. Por su parte, los gastos se han comportado con sentido anticíclico en recesiones y sin un perfil claramente definido en expansiones (Figura 1). Además, estos últimos tienen una mayor vocación amortiguadora que aquellos, claramente en momentos de crisis, y con menos nitidez en coyunturas de crecimiento.

No es frecuente la utilización contemporánea de ingresos y gastos, y menos que ambos tengan una orientación anticíclica. Es más, ingresos y gastos actúan frecuentemente en direcciones opuestas. Especialmente en coyunturas recesivas, el estímulo aportado por los gastos es contrarrestado en muchas ocasiones por los ingresos (Figura 1, panel izquierdo). Como cifra suficientemente elocuente diremos que de las 36 ocasiones en que el gasto de tipo discrecional ha actuado para impulsar la demanda durante las recesiones, en 25 de ellas (dos de cada tres) los ingresos discrecionales han aumentado, actuado así de manera contractiva sobre la economía.

${ }^{10}$ Los datos relativos a ingresos y gastos ajustados de ciclo no son proporcionados por la OCDE. La Unión Europea, debido a su importancia instrumental para el seguimiento del Pacto de Estabilidad y Crecimiento, sí los calcula y publica para los países miembros. Por esta razón, el análisis que sigue se circunscribe a los miembros de la Unión Europea que forman parte de la OCDE. Se trata de: Bélgica, Dinamarca, Alemania, Irlanda, Grecia, España, Francia, Italia, Holanda, Austria, Portugal, Finlandia, Suecia y Reino Unido. 


\section{Figura 1}

Respuesta activa de ingresos y gastos ajustados de ciclo. Los círculos muestran el número de casos de cada posible situación; las intercesiones, la actuación simultánea, que puede ser en el mismo sentido o en sentido contrario

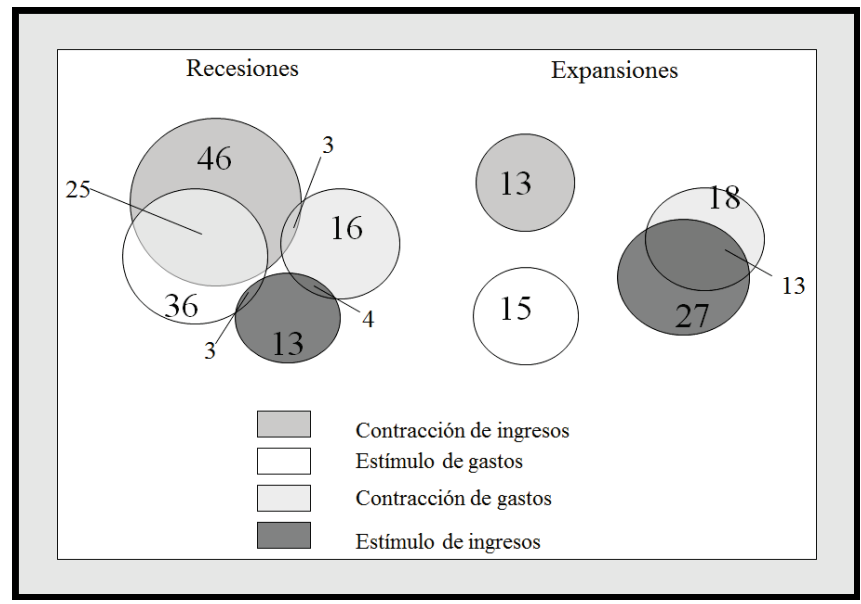

Fuente: Elaboración propia a partir de AMECO Database.

\subsection{Respuesta fiscal no lineal o la importancia de la situación fiscal previa}

Sin duda, las decisiones de los Gobiernos dependerán del margen de maniobra disponible, el denominado fiscal space. Los intereses o los deseos del Gobierno serán unos, pero las posibilidades reales pueden ser otras muy distintas. Con el fin de analizar cómo la situación fiscal de partida puede condicionar la práctica política, hemos examinado el estado de los siguientes variables: deuda pública, déficit fiscal y tamaño del Gobierno. Los datos muestran que la posición de partida no afecta en ningún caso a la respuesta fiscal cuando la economía se encuentra en momentos expansivos o de estabilidad, pero tanto la deuda pública como el saldo fiscal condicionan poderosamente la respuesta fiscal en situaciones recesivas (Tabla 3), aunque no así el tamaño del Gobierno.

El nivel medio de la ratio deuda pública/PIB en la combinación "recesión económica-estímulo fiscal" ha sido del $38,0 \%$. Sin embargo, la ratio alcanza un valor de 64\% en la combinación "recesión económica-ajuste fiscal" (Tabla 3).

El saldo fiscal previo también condiciona las decisiones de política económica, especialmente en épocas recesivas, en las que el saldo primario ${ }^{11}$ ha sido en promedio del $-2,5 \%$ del PIB cuando la respuesta fiscal ha sido de ajuste, frente a un valor del $-0,9 \%$ cuando la respuesta ha sido expansiva. Es decir, si

${ }^{11}$ Se ha escogido el déficit primario para este punto (en lugar del déficit estructural), porque pensamos que es la variable fiscal de referencia para los Gobiernos. 
los Gobiernos se encuentran en una situación presupuestaria claramente deficitaria, el margen de maniobra para un plan de estímulo es escaso, porque acentuaría el saldo negativo y, consiguientemente, incrementaría la deuda.

Tabla 3

Condiciones de partida en situaciones de recesión

\begin{tabular}{lccc} 
& \multicolumn{3}{c}{ Política fiscal } \\
\cline { 2 - 4 } & Estímulo & Ajuste & Neutral \\
\cline { 2 - 4 } Deuda Pública & $38 \%$ & $64 \%$ & $62 \%$ \\
Saldo primario & $-0,9 \%$ & $-2,5 \%$ & $-1,2 \%$ \\
\hline
\end{tabular}

Cálculo: para cada país y año en recesión, se ha calculado el promedio de la deuda (o del saldo primario) de ese año y los dos anteriores. De todos estos valores se ha calculado luego el promedio simple para los tres tipos de respuesta fiscal.

Fuente: Elaboración propia a partir de OCDE Economic Outlook Database.

El tercer factor que analizamos es el tamaño del Gobierno. Las variables proxy utilizadas han sido: ingresos totales (que incluyen el componente estructural, el componente cíclico y los intereses devengados), gastos totales (con el mismo contenido que el anterior), gastos estructurales (que no incorpora ni el componente cíclico ni los intereses sobre la deuda pública) e ingresos estructurales. La valoración general que hacemos es que el tamaño del Gobierno no desempeña un papel determinante en las decisiones fiscales. En ninguno de estos conceptos observamos un comportamiento fiscal suficientemente diferenciado en alguno de los tres escenarios económicos.

\subsection{El contexto monetario}

La política fiscal también afecta a la demanda agregada de manera indirecta, especialmente a través de su incidencia en los tipos de interés reales. En la medida en que se incrementa directamente la demanda agregada, un estímulo fiscal presiona los precios al alza, lo que a su vez empuja a los tipos de interés nominales, que incidirán negativamente tanto sobre la inversión como sobre el consumo privado, compensando total o parcialmente (efecto crowding-out) el impacto directo sobre la demanda de la política fiscal. Pero si el tipo de interés nominal se mantiene inalterado por la autoridad monetaria (se "acomoda" a la política fiscal), el tipo de interés real se reducirá, acentuando el impulso generado por la actuación fiscal. En el caso extremo, esto es, cuando los tipos de interés nominales están cercanos a cero, un incremento en el gasto público no 
desencadenará ningún tipo de efecto expulsión sobre la inversión o el consumo privados, obteniéndose los mayores multiplicadores ${ }^{12}$.

En este apartado estudiamos las condiciones monetarias en que se ha producido la política fiscal, es decir, si el contexto de política monetaria ha sido rígido o laxo, para lo cual analizamos la variación anual de los tipos de interés nominales a corto plazo. Se han realizado cálculos para el conjunto de las economías de la OCDE incluidas en este estudio y para sus dos subgrupos: la UE11 y el resto de países OCDE. Los resultados más relevantes se muestran en la Tabla 4, que contiene, para cada combinación de situación económica y política fiscal, las modificaciones habidas en los tipos de interés. Los comentarios que nos sugieren estos datos son:

- Frente a la política fiscal, la monetaria sí tiene una vocación claramente estabilizadora. Quiere decirse que, cuando la política fiscal ha sido anticíclica, la política monetaria ha tenido el mismo sentido, pero en aquellas ocasiones en que ha actuado a favor del ciclo, la política monetaria ha sido generalmente anticíclica.

- Se confirma la mayor actividad de la política monetaria frente a la fiscal. En coyunturas de expansión o recesión en las que la respuesta fiscal discrecional ha sido neutral (recuérdese la Tabla 1), la política monetaria ha reaccionado con una elevación media de los tipos de interés de 1,3 puntos porcentuales en el primer caso y una disminución media de 1,5 puntos en el segundo. La naturaleza estabilizadora de la política monetaria se reafirma con los datos mostrados en la última columna de la Tabla 4, correspondiente a entornos de economía plana: las modificaciones de los tipos de interés han sido sustancialmente menores; por el contrario, ya hemos comprobado que existe abundante actividad fiscal discrecional en esas situaciones, lo que confirma su afectación por otros factores, no ya distintos de la mera suavización del ciclo, sino incluso de carácter no estrictamente económico.

- Las variaciones de los tipos de interés no guardan relación con la respuesta de la política fiscal. Es decir, no advertimos ninguna vinculación entre la reacción fiscal y la respuesta monetaria, lo que nos lleva a concluir que la política monetaria no ha actuado intencionadamente como contrapeso de la política fiscal, sino que ha tenido su propio patrón de comportamiento, lo cual no debe sorprendernos dada la autonomía de actuación de la mayoría de los bancos centrales, que excluye cualquier tipo de colaboración explícita entre la instancia fiscal y la monetaria.

\footnotetext{
${ }^{12}$ No obstante, hay que decir que para una mayor eficacia de la política fiscal no basta con que los tipos de interés se acomoden; como ha señalado Buiter, si el crédito no fluye (esto es, si la velocidad de circulación del dinero es baja) la eficacia de la política fiscal se diluye (Buiter, 2009).
} 


\section{Tabla 4}

Marco monetario: variación anual de los tipos de interés nominales a corto plazo (puntos porcentuales)

\begin{tabular}{lccc} 
& \multicolumn{3}{c}{ Situación económica } \\
\cline { 2 - 4 } & $+1,3$ & Recesión & Plana \\
\cline { 2 - 4 } & $+0,9$ & $-2,0$ & $-0,5$ \\
Impulso fiscal & $+1,3$ & $-0,9$ & $-0,3$ \\
Ajuste fiscal & $-1,5$ & $-0,1$ \\
\hline Política fiscal neutral & +0.0 & \multicolumn{3}{c}{ Expansión } & \\
\hline
\end{tabular}

Fuente: Elaboración propia a partir de OCDE Economic Outlook Database.

\section{DISCUSIÓN DE RESULTADOS Y CONSECUENCIAS DE POLÍTICA ECONÓMICA}

En este estudio se ha pretendido caracterizar el comportamiento de la política fiscal discrecional de los países desarrollados a lo largo de las últimas décadas.

Nuestros resultados confirman la escasa utilización de la política fiscal para reducir las oscilaciones de las economías durante este periodo y, a la vez, la notable actividad fiscal al margen del ciclo. Los valores obtenidos son consistentes con los del FMI (2008, Figura 5.1 superior) y Leigh y Stehn (2009, Table 1), y nos sugieren que a través de la política fiscal, los Gobiernos persiguen otros fines, como la consolidación fiscal o el desarrollo económico, a los que en ocasiones se subordina la estabilización económica. Así, un comportamiento procíclico en una situación alcista de la economía puede deberse a que la generación de empleo sea nula o insuficiente en opinión del Gobierno (por ejemplo, porque el crecimiento del PIB se esté basando en el aumento de la productividad). En este caso, la meta del empleo prevalecería sobre la de la estabilización. Una segunda posibilidad es que el Gobierno se encuentre inmerso en un proceso de aumento de capital público a largo plazo (papel de la política físcal ligado al crecimiento) que se desarrolla, temporalmente, en una coyuntura alcista, actuando de esta forma el gasto público a favor del ciclo. Por su parte, las políticas de carácter contractivo pueden estar ligadas bien a reformas de carácter estructural, como la del sistema de pensiones, bien a procesos de ajuste fiscal orientados a la reducción de la deuda. También los estudios econométricos confirman este punto. Es frecuente encontrar que los coeficientes de las regresiones de los saldos fiscales sobre el output-gap no son estadísticamente significativos, independientemente de su signo. Así ocurre por ejemplo en Galí y Perotti (2003) y Fatás y Myhov (2009), lo que significaría, según estos últimos autores, que la respuesta activa de los Gobiernos no existe frecuentemente -como hemos comprobado-, o que dicho comportamiento no es consis- 
tente: unas ocasiones es procíclico y otras contracíclico (Fatás y Myhov, 2009, p. 21).

Se ha aducido en no pocas ocasiones que uno de los factores que afecta al débil papel anticíclico de la política fiscal es el relacionado con los retardos, de manera que debido al tiempo que media desde que se identifica la necesidad de una actuación hasta su ejecución, ésta puede producirse cuando el ciclo ya ha cambiado de signo, y el efecto real ser incluso el contrario al deseado. Nos estamos refiriendo a los denominados retardos internos (inside lags en su acepción inglesa), distintos de los retardos externos (outside lags), que hacen referencia al tiempo que media entre la ejecución de la política fiscal y sus efectos sobre la economía ${ }^{13}$. Por nuestra parte, no hemos encontrado evidencia empírica del comportamiento procíclico asociado al retardo en la implementación de las políticas fiscales ${ }^{14}$. A este fin, se han analizado aquellos episodios en los que la respuesta fiscal discrecional es procíclica para ver si en realidad es la reacción a la situación económica del ejercicio anterior, implementada con retraso y cuando la posición cíclica de la economía ha cambiado. Se ha encontrado sólo un caso, que nos conduce a rechazar este supuesto; se trata del Reino Unido, con recesión económica y política fiscal de ajuste en 1980, que sin embargo puede ser la respuesta a la situación económica expansiva de 1979. A similares conclusiones se llega en Leigh y Stehn (2009): al comparar la función de respuesta de la política fiscal y de la política monetaria, encuentran que aquella adolece de menores retardos de lo que convencionalmente se piensa, especialmente en los países anglosajones y que, en definitiva, su efectividad depende del instrumento fiscal utilizado.

Esta pasividad anticíclica de la política fiscal se hace más evidente en los países integrantes de la UEM, conclusión a la que también llegan otros autores, por ejemplo Fatás y Myhov (2009, Cuadro 1). La filosofía implícita primero en el Tratado de Maastricht y posteriormente en el Pacto de Estabilidad y Crecimiento (y explicitada en numerosas ocasiones ${ }^{15}$ ) asume que las políticas fiscales discrecionales no suelen ser las idóneas para la gestión a corto plazo de la demanda, y que ha de producirse un predominio de las reglas frente a la discrecionalidad, con el fin de que la política monetaria, considerada como el principal elemento de gestión de la demanda agregada, pueda aplicarse en un marco predecible, y el papel contracíclico de la política fiscal se limite al que puedan

\footnotetext{
${ }^{13}$ El retraso de las medidas discrecionales para suavizar el ciclo ha justificado tradicionalmente el creciente peso de los estabilizadores automáticos (Peacock y Shaw, 1974, p. 146).

${ }^{14} \mathrm{Al}$ trabajar con datos anuales estas hipotéticas situaciones son menos perceptibles que con datos trimestrales.

${ }^{15}$ Ver, en este sentido: BCE (2001, 2003 y 2004) y Comisión Europea (2001).
} 
jugar los estabilizadores automáticos ${ }^{16}$. Es lo que Galí y Perotti denominan "la subrogación de la política fiscal" (Galí y Perotti, 2003, p. 555). En parecidos términos se expresan Deroose et al. (2008, p. 7), para quienes a partir de 1992 se produce un cambio de sentido en la política fiscal discrecional de los países que posteriormente adoptaron el euro: desde procíclica en cualquier tipo de situación hasta acíclica en expansiones y contracíclica en recesiones. Una valoración similar sugieren Galí y Perotti, para quienes hay poca evidencia práctica del denunciado sesgo procíclico del Tratado de Maastricht y del Pacto de Estabilidad y Crecimiento (Galí y Perotti, 2003, 564) ${ }^{17}$. Pero como ya hemos comentado, lo que confiere a la política fiscal en la zona euro ese carácter acíclico no es tanto el resultado de las políticas, anticíclicas en ocasiones y procíclicas en otras, sino su escasa actividad, su desaparición como instrumento de gestión de la demanda agregada.

Cuando ha existido actividad fiscal, hemos comprobado su comportamiento asimétrico en relación al ciclo, a favor en expansiones y ligeramente en contra en recesiones, lo que supone que en no pocas ocasiones los Gobiernos actúan desestabilizando la actividadad económica, ampliando las desviaciones respecto de la tendencia. Como se ha afirmado en numerosos estudios, los Gobiernos responden asimétricamente, estimulando la economía en situaciones recesivas, pero no frenándola con el mismo énfasis en situaciones expansivas, desaprovechando muchas ocasiones para mejorar sus saldos fiscales. Se han señalado razones de oportunismo político para este comportamiento. Afonso y Hauptmaier concluyen por ejemplo que, en época electoral, los Gobiernos tienden a realizar una política fiscal más expansiva para ganar votos (Afonso y Hauptmaier, 2009, p. 12). A similar conclusión llegan Sutherland et al. (2010): si los electores subestiman el coste futuro de la deuda (comportamiento no-ricardiano), los políticos estarán tentados, en época electoral, de incrementar el gasto público y financiarlo mediante la emisión de deuda. Una explicación adicional viene dada por el llamado "efecto voracidad", en referencia a la pugna establecida entre los diferentes centros de poder para captar una mayor porción de la tarta del gasto, que será especialmente intensa en épocas de bonanza económica, de manera que el gasto público aumentará más de lo que proporcionalmente

\footnotetext{
16 "La consideración de los estabilizadores automáticos y no las medidas discrecionales como el principal instrumento presupuestario para suavizar las fluctuaciones económicas en la UEM está en consonancia con el Pacto de Estabilidad y Crecimiento; fijese un objetivo a medio plazo y dejemos a los estabilizadores automáticos actuar libre y simétricamente a lo largo del ciclo" (Comisión Europea, 2001, p. 63). (La traducción es propia)

${ }^{17}$ El alcance temporal del trabajo de Galí y Perotti finaliza en 2001 y, como afirman los autores, desde la aprobación del Tratado de Maastricht y hasta ese momento no se había producido en la zona euro ningún episodio de recesión verdaderamente profunda, por lo que advierten del riesgo de extrapolar sus conclusiones a momentos en los que la economía se encuentre en una situación cíclica extrema.
} 
correspondería con el incremento de la producción nacional (Perotti, 2007, p. 23 y Alesina et al. 2008, p. 1030 ${ }^{18}$. Este comportamiento asimétrico confiere a la política fiscal discrecional un sesgo hacia el incremento de la deuda y el deterioro de las finanzas públicas. Las alternativas sugeridas por la literatura para modificar esta tendencia se refieren al fortalecimiento del marco institucional, de manera que el desempeño fiscal dependa menos del ciclo político. Son tres los ámbitos posibles de actuación: la creación de órganos fiscales más o menos independientes de los poderes públicos, la implantación de reglas para el control de los agregados fiscales y, por último, la aprobación de leyes orientadas a asegurar el futuro de las finanzas públicas.

El diferente carácter estabilizador de ingresos y gastos, que es claramente procíclico en el primer caso mientras que los gastos actúan frecuentemente con sentido anticíclico en recesiones y sin una orientación definida en expansiones, es consistente con Égert (2010, p. 8). Además, no hemos observado una modificación de este comportamiento a lo largo del tiempo, frente a Fatás y Myhov (2009 p. 26), quienes encuentran una tendencia hacia una mayor proclicidad en los gastos y una mayor contraciclicidad en los ingresos. La explicación de esta discrepancia puede ser de tipo metodológico: en nuestro trabajo se han fijado unos valores de corte para delimitar lo que es o no es una variación significativa en los ingresos y gastos estructurales, mientras que la investigación de estos autores se sustenta en regresiones econométricas, no descartando a priori ningún dato.

Un aspecto del que apenas existen referentes en la literatura es el comportamiento cíclico de ingresos y gastos cuando son utilizados de manera simultánea, y el elevado número de casos en que actúan en sentido cíclico contrario. Una situación típica sería aquella en la que el Gobierno ejecuta un programa de gastos para impulsar la economía (por ejemplo mediante obras públicas o aumentando la cobertura por desempleo) y, simultáneamente, eleva algunos impuestos para no deteriorar en exceso el presupuesto. Como el multiplicador del gasto es más eficaz a corto plazo que el de los impuestos, es posible que, en cuanto al impacto económico inmediato, esta estrategia tenga sentido; sin embargo, desde el punto de vista de la respuesta fiscal, puede ocurrir que el efecto neto sobre el saldo estructural primario sea incluso nulo, difuminando la actuación fiscal. Diríamos que cuando el objetivo de los Gobiernos es el de la consolidación fiscal, ingresos y gastos sí se mueven en el mismo sentido, pero es posible que actúen en dirección opuesta cuando el fin es la estabilización económica

El papel limitativo que supone para la política fiscal la situación de partida de las finanzas públicas conducirá a los Gobiernos fuertemente endeudados a

${ }^{18}$ Una conclusión perversa de este razonamiento (Lane, 2003), es que la dispersión del poder favorece la actividad fiscal procíclica, de manera que un gobierno unipersonal sería el que tendría un menor "efecto voracidad" y en consecuencia un menor sesgo procíclico. 
priorizar la consolidación fiscal frente a la estabilización del ciclo, reduciéndose en consecuencia el espacio para la política fiscal de gestión de la demanda y alterando el orden de prioridades: primero la consolidación fiscal, luego la reducción del ciclo (Debrun y Kapoor, 2010, p. 12). Égert (2010, p. 15) calcula que para niveles de deuda superiores al $89 \%$, la política fiscal en las economías de la OCDE es procíclica, para niveles entre el $30 \%$ y el $89 \%$ es acíclica o ligeramente anticíclica, y solo para valores inferiores al $30 \%$ es claramente anticíclica. Adicionalmente, la efectividad de la política fiscal discrecional puede verse mermada a medida que aumenta el nivel de deuda, si se asume la validez (aunque sea parcial) de la equivalencia ricardiana: cuanto mayor volumen de deuda, más incrementarán los ciudadanos su tasa de ahorro para el pago futuro de la misma, compensando el aumento de renta disponible originado en el estímulo fiscal del Gobierno. En cuanto a la importancia del saldo fiscal previo, Égert fija un límite en el déficit del 2,7\% para identificar el sesgo cíclico del balance primario: para valores inferiores la respuesta del saldo primario será anticíclica, y procíclica para valores superiores (Égert, 2010, p. 15). Desde el punto de vista de los instrumentos de política económica, el factor restrictivo que suponen la deuda pública y el saldo fiscal existente significa que, en un entorno recesivo de la economía, la única herramienta para impulsar la economía sea la política monetaria.

Nuestra conclusión de que el tamaño del Gobierno no importa para la respuesta cíclica de la política fiscal merece una aclaración. Estamos comparando tamaño de la administración pública con la respuesta fiscal discrecional, pero también hay que considerar el papel de los estabilizadores automáticos, que sí suelen estar positivamente correlacionados con la dimensión del Gobierno, por lo que la respuesta fiscal total a las oscilaciones cíclicas de la economía será tanto mayor cuanto mayor sea éste. Esta es la razón por la que la sensibilidad del presupuesto total al ciclo económico es mayor en aquellos países considerados socialmente más avanzados, con un mayor colchón de seguridad frente a las recesiones, como son Dinamarca, Suecia, Finlandia o Noruega (Comisión Europea, 2005, Tabla 2).

El hecho de que la política monetaria raramente se acomode a la actividad fiscal discrecional reduce las posibilidades para el análisis de la eficacia de la política fiscal en entornos no beligerantes de los tipos de interés, y muestra una preferencia generalizada entre los Gobiernos por la estabilidad de los precios frente a la estabilidad económica. Los trabajos empíricos que han estimado el signo y dimensión de los multiplicadores fiscales muestran que una política monetaria que no reaccione o lo haga sólo parcialmente frente a un programa de impulso fiscal aumentará notablemente la eficacia de ésta ${ }^{19}$. Esto nos lleva a

${ }^{19}$ Christiano et al. (2011) obtienen un multiplicador de 3,9 cuando los tipos de interés se mantienen inalterados y de 0,9 cuando los tipos de interés se determinan siguiendo una regla de 
considerar la conveniencia de una adecuada articulación de las dos herramientas, la fiscal y la monetaria, con el fin de maximizar el rendimiento de la primera, especialmente en momentos de recesión profunda o cuando la política monetaria no es capaz por sí misma de impulsar la economía, ya sea porque los tipos de interés se encuentren próximos a cero, o porque los mecanismos del crédito no funcionen adecuadamente.

\section{REFERENCIAS BIBLIOGRÁFICAS}

AFONSO, A. y HAUPTMEIER, S. (2009): "Fiscal behaviour in the European Union. Rules, fiscal decentralization and government indebtness". ECB Working Paper Series, 1054.

AKERLOF, G. y SHILLER, J. (2009): Animal Spirits, Princeton (New Jersey): Princeton University Press.

ALESINA, A.; CAMPANTE, F. y TABELLINI, G. (2008): "Why is fiscal policy often prociclycal?". Journal of the European Economic Association, 6, pp. 1006-1036.

ALESINA, A. y PEROTTI, R. (1995): "Fiscal expansions and adjustments in OECD economies", Economic Policy, 21, pp. 207-248.

ALESINA, A. y PEROTTI, R. (1997): "Fiscal adjustments in OECD countries: composition and macroeconomic effects". IMF Staff Paper, 44.

ALMUNIA, M.; BÉNÉTRIX, A.; EICHENGREEN, B. y O’ROURKE, K. (2009): "From great depression to great credit crisis: similarities, differences and lessons". Economic Policy, Abril, pp. 219-265.

AUERBACH, A. y GORODNICHENKO, Y. (2010): "Measuring the ouput responses to fiscal policy". NBER TAPES conference on Fiscal Policy, Varenna, Junio.

BANCO CENTRAL EUROPEO (2001): "Política fiscal y crecimiento económico". Boletín Mensual (Agosto).

BANCO CENTRAL EUROPEO (2003): "La relación entre la política monetaria y las políticas fiscales de la zona del euro". Boletín Mensual (Febrero).

BANCO CENTRAL EUROPEO (2004): "La UEM y la dirección de las políticas fiscales". Boletín Mensual (Enero).

actuación vinculada a la inflación; el FMI (2008), proporciona un multiplicador de los impuestos que en el primer año es igual a 1 sin acomodo monetario, y de 1,9 con acomodo; en Coenen et al. (2012), en fin, se simulan un total de siete modelos para EE.UU. y la zona euro bajo tres escenarios monetarios -no acomodo, acomodo durante un año y acomodo durante dos años-, con la conclusión general de que se produce un incremento tendencial de los multiplicadores a medida que la política monetaria se vuelve más acomodatícia. 
BANCO DE ESPAÑA (2006): "Los efectos económicos de la política fiscal en España”. Boletin Económico (marzo, pp. 116-128)

BARRO, R.J. y REDLICK, C.J. (2009): "Macroeconomic Effects from Government purchases and Taxes". NBER WP, 15369.

BAUNSGAARD, T. y SYMANSKY, S. (2009): "Automatic fiscal stabilizers". IMF SPN, 09/23

BERNANKE, B. (2008): Conferencia en la Universidad de Harvard, Cambridge, Massachusetts, 4 de junio. Disponible online en http://www.federalreserve.gov/newsevents/speech/bernanke20080604a.htm

BLANCHARD, O. (1990): "Suggestions for a new set of fiscal indicators". OCDE Working Paper, 79.

BLANCHARD, O. y PEROTTI, R. (2002): "An empirical characterization of the dynamic effects of changes in Government spending and taxes on output". The Quarterly Journal of Economics, 117 (4), pp. 1329-1368

BLINDER, A. (2006): "The case against the case against discretionary fiscal policy". En Kopcke, R.W., Tootell, M.B. y Triest, K. (ed.): The macroeconomics of fiscal policy. MIT Press, Cambridge, EE.UU., pp. 25-74.

BUITER, W. (2009): "Is there a case for a further co-ordinated global fiscal stimulus?"

http://blogs.ft.com/maverecon/2009/09/is-there-a-case-for-a-further-coordinated-global-fiscal-stimulus-part-2/\#axzz1ojrBrsfo

CASTELLS, A. y DURÁN, JM. (coords.) (2004): Las nuevas fronteras del sector público ante la globalización, Madrid - Barcelona, Ed. Marcial Pons.

CHRISTIANO, L.; EICHENBAUM, M. y REBELO, S. (2011): "When is the Government spending multiplier large?". Journal of Political Economy, 119 (1), pp. 78-121.

CIMADOMO, J. (2011): "Real-time data and fiscal policy analysis". ECB Working Paper Series, 1408.

COENEN, G.; ERCEG, C.; FREEDMAN, CH.; FURCERI, D.; KUMHOF, M.; LALONDE, R.; LAXTON, D.; LINDÉ, J.; MOUROUGANE, A.; MUIR, D.; MURSULA, S.; RESENDE, C.; ROBERTS, J.; ROEGER, W.; SNUDDEN, S.; TRABANDT, M. y VELD, J. (2012): "Effects of Fiscal Stimulus in Structural Models." American Economic Journal: Macroeconomics, 4(1), pp. 22-68.

DOI:10.1257/mac.4.1.22

COGAN, J.; CWIK, T.; TAYLOR, J. y WIELAND, V. (2009): "New Keynesian versus old Keynesian government spending multipliers". ECB Working Paper Series, 1090.

COMISIÓN EUROPEA (2001): Public finances in EMU-2001, Directorate General for Economic and Financial Affairs (otoño). 
COMISIÓN EUROPEA (2005): New and updates budgetary sensitivities for the EU budgetary surveillance, Directorate General for Economic and Financial Affairs (septiembre).

DAGUM, E. (2010): "Business cycles and current economic analysis". Estudios de Economía Aplicada, 28(3), pp. 577-594.

DE CASTRO, F. y HERNANDEZ DE COS, P. (2008): "The economic effects of fiscal policy: the case of Spain". Journal of Macroeconomics, 30, pp. 10051028.

DE GRAUWE, P. (2010): "Fiscal policies in "normal" and "abnormal" recessions". Voxeu.org, 30 de marzo.

DEBRUN, X. y KAPOOR, R. (2010): "Fiscal policy and macroeconomic stability: automatic stabilizers work, always and everywhere". IMF Working Paper, 111.

DEROOSE, S.; LARCH, M. y SCHAECHTER, A (2008): "Constricted, lame and procyclical?. Fiscal policy in the euro area revisited". European Commision, Economic and Financial Affairs Economic Papers, 353.

ÉGERT, B. (2010): "Fiscal policy reaction to the cycle in the OECD: Pro- or Counter-cyclical?". OCDE Economic Deparment Working Paper, 763.

EICHENGREEN, B. (2000): La globalización del capital, (1996). Barcelona: Antoni Bosch Ediciones. $1^{a}$ edición en castellano.

FATÁS, A. y MIHOV, I. (2009): "The euro and fiscal policy". NBER Working Paper, 14722.

FMI (2008): "Fiscal Policy as a countercyclical tool". WEO (octubre)

FMI (2010): "Will it hurt? Macroeconomic effects of fiscal consolidation". WEO, octubre, Chapter 3.

FREEDMAN, C.; KUMHOF, M.; LAXTON, D. y LEE, J. (2009): "The case for global fiscal stimulus". IMF SPN 09/03.

GARCíA, A. (2010): "Oferta y demanda y el ciclo económico: una interpretación de la situación económica actual”. Estudios de Economía Aplicada, 28(3), pp. 671-686.

GALÍ, J. y PEROTTI, R. (2003): "Fiscal policy and monetary integration in Europe". Economic Policy (octubre), pp. 533-572.

GARRET, G. (1998): "Global markets and national politics: collision course o virtuous circle?". International Organization, 52 (4), pp. 787-824.

GIAVAZZI, F. y PAGANO, M. (1990): "Can severe fiscal contractions be expansionary?. Tales of two small European countries". NBER Macroeconomics Annual, Volumen 5. ISBN: 0-262-02312-1

GIAVAZZI, F.; JAPPELLI, T.; PAGANO, M. y BENEDETTI, M. (2005): "Searching for non-monotonic effects of fiscal policy: new evidence". Monetary and Economic Studies (special edition), octubre, pp. 197-232. 
GIROUARD, N. y ANDRÉ, C. (2005): "Measuring Cyclically adjusted Budget Balances for OECD Countries". OECD Economics Department Working Papers, 434.

HEMMING, R.; KELL, M. y MAHFOUZ, S. (2002): "The effectiveness of fiscal policy in stimulating economic activity - A review of the literature". IMF Working Paper, 02/208.

KAMINSKY, G.; REINHART, C. y VÉGH, C. (2004): "When it rains, it pours: procyclical capital flows and macroeconomic policies". NBER working Paper, 10780

KEOANE, R. (2002): Power and governance in a partially globalized world. Londres: Routledge. ISBN 0415288193.

KRUGMAN, P. (2008): "La hora de la política fiscal". EL PAIS-NEGOCIOS. 1910-2008

LANE, P. (2003): "The cyclical behaviour of fiscal policy: evidence from the OECD". Journal of Public Economics, 87, pp. 2661-2675.

LEIGH, D. y STEHN, J. (2009): "Fiscal and Monetary Policy During Downturns: Evidence from the G7". IMF Working Paper 09/50.

MANKIW, N.G.(2000): "The savers-spenders theory of fiscal policy". The American Economic Review, 90 (2), pp. 120-125.

MINSKY, H. (1986): Stabilizing an Unstable Economy. Yale University Press.

MOUNTFORD, A. y UHLIG, H. (2008): "What are the effects of fiscal policy shocks?". NBER Working Paper, 14551.

NORDHAUS, W. (1975): "The Political Business Cycle". Review of Economic Studies. 42, pp. 169-190.

OBSTFELD, M. (1998): "The Global Capital Market: Benefactor or Menace?". Journal of Economic Perspectives, 12(4), pp. 9-30.

OCDE (2011): Sources \& Methods of the OECD Economic Outlook. URL permanente

(http://www.oecd.org/document/14/0,3343,en_2649_34573_1847822_1_1_1 1,00.html)

PARKER, J. (2011): "On measuring the effects of fiscal policy in recessions". Journal of Economic Literature, 49(3), pp. 703-718.

PEACOCK, A. y SHAW, G.K. (1974): La teoría económica de la política fiscal. Méjico D.F.: Fondo de Cultura Económica.

PEROTTI, R. (2002): "Estimating the effects of fiscal policy in OECD countries". ECB Working Papers Series, 168.

PEROTTI, R. (2007): "Fiscal policy in developing countries: a framework and some questions". Policy Research WP 4365.

PHILLIPS, A. W. (1958): "The relation between unemployment and the rate of change of money wage rates in the United Kingdom, 1861-1957". Económica, 25, pp. 283-99. 
PRICE, R. (2010): "The Political Economy of Fiscal Consolidation". OECD Economics Department Working Papers, 776.

RAMEY, V. (2011a) "Can Government purchases stimulate the economy". Journal of Economic Literature, 49, pp. 673-85.

RAMEY, V. (2011b): "Identifying Government spending shocks: It's all in the timing". Quarterly Journal of Economics, 126, pp. 1-50.

RICARDO, D. (1888): "Essay on the funding system". The Works of David Ricardo. J.R. McCulloch. Londres: Ediciones John Murray.

RODRIK, D. (2007): "How to save globalization from its cheerleaders". CEPR Discussion Paper Series, 6494.

ROMER, C. y D. ROMER (2010): "The macroeconomic effects of tax changes: estimates based on a new measure of fiscal shocks". American Economic Review, 100, pp. 763-801.

SAMUELSON, P. (1939): "Interactions between the multiplier analysis and the principle of accelerator". The Review of Economics and Statistics, 21(2), pp. 75-78.

SARGENT, T. J. y WALLACE, N. (1976): "Rational expectations and the theory of economic policy". Journal of Monetary Economics, 2, pp. 169-83.

SPILIMBERGO, A.; SYMANSKY, S. y SCHINDLER, M. (2009): "Fiscal multipliers". IMF SPN 09/11

SUTHERLAND, D. ; HOELLER, P. ; ÉGERT, B. y RÖHN, O. (2010) : "Countercyclical economic policy". OCDE Economic Department Working Paper, 760.

TANZI, V. (2000): "Globalization, technological developments, and the work of fiscal termites". Simposium "International tax policy in the new millennium", Brooklyn Law School.

TOBIN, J. (1977): "How Dead is Keynes?". Economic Inquiry, 15, pp. 459-468

WOLF, M. (2004 ): Why Globalization Works. New Haven: Yale University Press. ISBN: 0300102526

WOODFORD, M. (2009): "Convergence in macroeconomics: elements of the new synthesis". American Economic Journal: Macroeconomics, 1(1), pp. 267-279.

WYPLOSZ, CH. (2005): "Fiscal policy: institutions versus rules". National Institute Economic Review, 191, pp. 64-78. 


\section{Anexo 1}

Expansiones y recesiones económicas

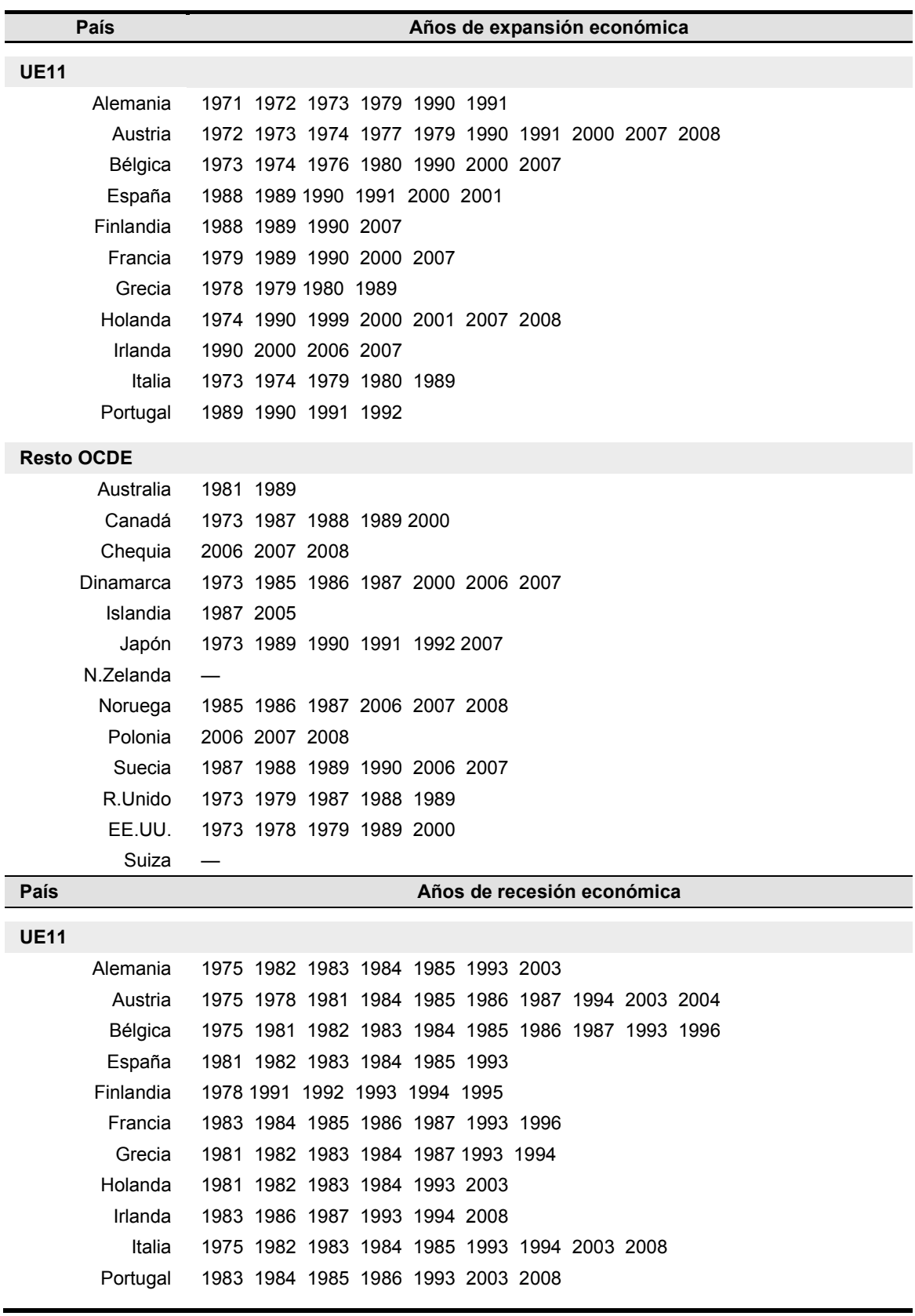




\section{Anexo 1 (Continuación)}

Expansiones y recesiones económicas

\begin{tabular}{|c|c|c|}
\hline País & & Años de recesión económica \\
\hline \multicolumn{3}{|l|}{ Resto OCDE } \\
\hline Australia & 1982198319901991 & 19921993 \\
\hline Canadá & 1982198319911992 & 19931996 \\
\hline Chequia & 199920022003 & \\
\hline Dinamarca & 1974197519801981 & 198219881991199219932008 \\
\hline Islandia & 1983198819911992 & 19931995 \\
\hline Japón & 1974197519761998 & 1999200220032008 \\
\hline N.Zelanda & 1988199019911992 & 19982008 \\
\hline Noruega & 1988198919901991 & \\
\hline Polonia & 20022003 & \\
\hline Suecia & 1977197819811982 & 198319911992199319942008 \\
\hline R.Unido & 1974197519801981 & 198219831984199119921993 \\
\hline EE.UU. & 1974197519801982 & 19831991 \\
\hline Suiza & 1991199319941995 & 199620032004 \\
\hline
\end{tabular}

Fuente: Elaboración propia a partir de OCDE Economic Outlook Database. 


\section{Anexo 2}

Episodios de política fiscal discrecional

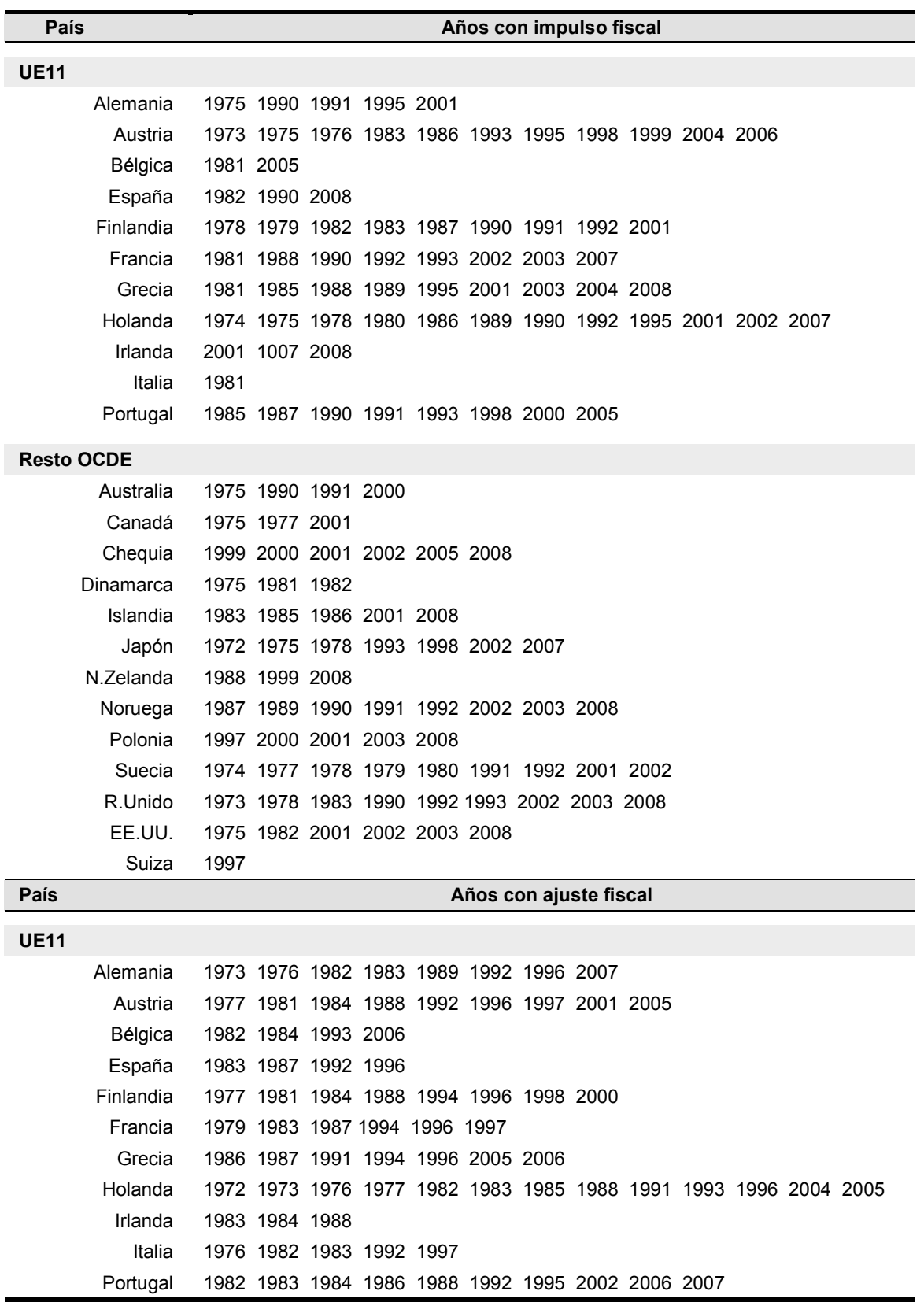


Anexo 2 (continuación)

Episodios de política fiscal discrecional

\begin{tabular}{|c|c|}
\hline País & Años con ajuste fiscal \\
\hline \multicolumn{2}{|l|}{ Resto OCDE } \\
\hline Australia & 1979198619871988199719982002 \\
\hline Canadá & 19811986198719961997 \\
\hline Chequia & 20042007 \\
\hline Dinamarca & 1973198319841985198620042005 \\
\hline Islandia & 1984199019952005 \\
\hline Japón & 1984199920012006 \\
\hline N.Zelanda & 19871989199119931994200020022005 \\
\hline Noruega & 19941995200020042006 \\
\hline Polonia & 199920052007 \\
\hline Suecia & $\begin{array}{lllllllll}1976 & 1981 & 1986 & 1987 & 1994 & 1996 & 1997 & 1998 & 2000\end{array}$ \\
\hline R.Unido & 1977198019821995199619971998 \\
\hline EE.UU. & 197219761981198719941997199820052006 \\
\hline Suiza & 19941995199920052006 \\
\hline
\end{tabular}

Fuente: Elaboración propia a partir de OCDE Economic Outlook Database. 


\section{Anexo 3}

Ciclo económico y política fiscal. 1970-2008

Número de casos

\begin{tabular}{|c|c|c|c|c|c|c|c|}
\hline & \multirow[b]{2}{*}{$\begin{array}{c}1=2+3+4=5+6+7 \\
N^{0} \text { de casos con } \\
\text { información de } \\
\text { output-gap y SEP }\end{array}$} & \multicolumn{3}{|c|}{ Output-gap } & \multicolumn{3}{|c|}{ Política fiscal } \\
\hline & & $\begin{array}{c}2 \\
\text { Significativamente } \\
\text { negativo } \\
\text { (recesión) } \\
\end{array}$ & $\begin{array}{c}3 \\
\text { Significativamente } \\
\text { positivo } \\
\text { (expansión) } \\
\end{array}$ & $\begin{array}{c}4 \\
\text { No } \\
\text { significativo }\end{array}$ & $\begin{array}{c}5 \\
\text { Impulso }\end{array}$ & Ajuste & $\begin{array}{c}7 \\
\text { No } \\
\text { activa }\end{array}$ \\
\hline OCDE & 736 & 165 & 112 & 459 & 140 & 152 & 444 \\
\hline UE11 & 365 & 81 & 62 & 222 & 71 & 77 & 217 \\
\hline \multicolumn{8}{|l|}{ UE11 } \\
\hline Alemania & 38 & 7 & 6 & 25 & 5 & 8 & 25 \\
\hline Austria & 38 & 10 & 10 & 18 & 11 & 9 & 18 \\
\hline Bélgica & 37 & 10 & 7 & 20 & 2 & 4 & 31 \\
\hline España & 28 & 6 & 6 & 16 & 3 & 4 & 21 \\
\hline Finlandia & 32 & 6 & 4 & 22 & 9 & 8 & 15 \\
\hline Francia & 30 & 7 & 5 & 18 & 8 & 6 & 16 \\
\hline Grecia & 32 & 7 & 4 & 21 & 9 & 7 & 16 \\
\hline Holanda & 37 & 6 & 7 & 24 & 12 & 13 & 12 \\
\hline Irlanda & 28 & 6 & 4 & 18 & 3 & 3 & 22 \\
\hline Italia & 38 & 9 & 5 & 24 & 1 & 5 & 32 \\
\hline Portugal & 27 & 7 & 4 & 16 & 8 & 10 & 9 \\
\hline \multicolumn{8}{|l|}{ Resto OCDE } \\
\hline Australia & 37 & 6 & 2 & 29 & 4 & 7 & 26 \\
\hline Canadá & 38 & 6 & 5 & 27 & 3 & 5 & 30 \\
\hline Chequia & 10 & 3 & 3 & 4 & 6 & 2 & 2 \\
\hline Dinamarca & 36 & 10 & 7 & 19 & 3 & 7 & 26 \\
\hline Islandia & 27 & 6 & 2 & 19 & 5 & 4 & 18 \\
\hline Japón & 37 & 8 & 6 & 23 & 7 & 4 & 26 \\
\hline N.Zelanda & 22 & 6 & 0 & 16 & 3 & 8 & 11 \\
\hline Noruega & 25 & 4 & 6 & 15 & 8 & 5 & 12 \\
\hline Polonia & 12 & 2 & 3 & 7 & 5 & 3 & 4 \\
\hline Suecia & 35 & 10 & 6 & 19 & 9 & 9 & 17 \\
\hline R.Unido & 36 & 10 & 5 & 21 & 9 & 7 & 20 \\
\hline EE.UU. & 38 & 6 & 5 & 27 & 6 & 9 & 23 \\
\hline Suiza & 18 & 7 & 0 & 11 & 1 & 5 & 12 \\
\hline
\end{tabular}

Output gap: Recesión = Brecha de producción (datos centrados) $<-1$ desviación típica Expansión = Brecha de producción (datos centrados) $>1$ desviación típica

No significativo = -1 desviación tipica < brecha de producción (datos centrados) $<1$ desviación típica

Política fiscal: Impulso: Variación anual del SEP $<-0,5$ desviación típica Ajuste: Variación anual del SEP $>+0,5$ desviación típica No activa: $-0,5$ desviación típica $<$ Variación anual del $S E P<+0,5$ desviación típica

Fuente: Elaboración propia a partir de OCDE Economic Outlook Database. 
